\title{
PATRIMÔNIO FERROVIÁRIO NO RIO GRANDE DO SUL: AS ESTAÇÕES PADRÃO VFRGS DOS ANOS 30 E 40. ESTUDO DE CASO DA ESTAÇÃO DE ALEGRETE (RS)
}

\author{
Patrimony railway in Rio Grande do Sul: the VFRGS standard \\ stations in the 30s and 40s. Case study of Alegrete (RS) station
}

\section{Renan Rosso Bicca}

Arquiteto e Urbanista, mestrando no PROGRAU/UFPEL (Pelotas, RS, Brasil).

\section{Laura Lopes Cezar}

Orientadora, Arquiteta e urbanista, professora do curso de Arquitetura e Urbanismo da UFPEL (Pelotas, RS, Brasil). Doutorado em Comunicación Visual en Arquitectura y Diseño pela Universidade Politécnica da Catalunha, Espanha.

\begin{abstract}
Resumo
O intuito da Pesquisa é apresentar a história das ferrovias no Brasil e Rio Grande do Sul. Analisar as estações ferroviárias padrão VFRGS no período dos anos 30 e 40. A implantação das ferrovias no Brasil, cujo início a partir de 1850, quando o império almejava consolidar-se enquanto nação e desvincular-se de Portugal. A primeira estrada de ferro é inaugurada em 1854. Após a construção da primeira linha ferroviária, as estradas de ferro começaram sua expansão pelo território brasileiro. Em 1874 é inaugurada a uma linha no Rio Grande do Sul, entre Porto Alegre e São Leopoldo. As estações foram implantadas no mesmo período das linhas férreas, muitas estações foram construídas por companhias estrangeiras e pelos Batalhões de Engenharia do Exército. Entre as décadas de 30 e 40 a VFRGS inaugurou estações ferroviárias padronizadas em diversos pontos do estado. A partir disso, constrói-se uma linha do tempo para melhor exemplificar as semelhanças compositivas entre os edifícios. Além disso, apresenta o processo de inserção da estação ferroviária em Alegrete/RS, estabelecendo um parâmetro com a realidade. Conclui-se que, as estações ferroviárias analisadas, embora com algumas variáveis, seguem um projeto padrão, resultando em estações férreas com forte identidade visual.
\end{abstract}

Palavras-chaves: Estação ferroviária. Padrão. VFRGS.

\begin{abstract}
The purpose of the survey is to present the history of the railways in Brazil and Rio Grande do Sul. To analyze the VFRGS standard railway stations in the 30s and 40s. The implementation of the railroads in Brazil, which began in 1850, when the empire consolidated as a nation and disassociated from Portugal. The first railway was inaugurated in 1854. After the construction of the first railway line, the railroads began to expand throughout the Brazilian territory. In 1874 a line in Rio Grande do Sul, between Porto Alegre and São Leopoldo was inaugurated. The stations were deployed in the same period of the railway lines, many stations were built by foreign companies and by the Army Engineering Battalions. Between the 1930s and 1940s, VFRGS inaugurated standard railway station sthroughout the state. From this, a timeline is constructed to better exemplify the compositional similarities between buildings. In addition, it presents the process of insertion of the railway station in Alegrete/RS, establishing a parameter with reality. It can be concluded that the analyzed railway stations, although with some variables, follow a standard design, resulting in railway stations with strong visual identity.
\end{abstract}

Keywords: Railway station. Standard. VFRGS. 


\section{Sumário}

1. Introdução; 2. Metodologia; 3. Resultados e discussão; 3.1 A origem das ferrovias; 3.2 As ferrovias no Brasil; 3.3 As ferrovias no Rio Grande do Sul; 3.4 Estações ferroviárias; 3.5 Tipologia das estações ferroviárias; 4. Conclusão; 5. Notas; Referências

\section{INTRODUÇÃO}

A inserção do transporte ferroviário no Brasil contribuiu para o desenvolvimento das cidades, pois simultaneamente a implantação da linha férrea os serviços de iluminação, educação, saúde e telégrafos chegavam nos municípios. Além disso, juntamente com a expansão da malha ferroviária pelo Rio Grande do Sul, foram inauguradas as Estações Ferroviárias.

As tipologias arquitetônicas das estações são típicas em função do tempo, havendo estações ferroviárias similares em cidades distintas, normalmente relacionadas na mesma linha férrea, isso deve-se ao fato de as estações pertencerem a mesma empresa que administra a ferrovia. Os prédios eram compostos por materiais e técnicas construtivas inovadoras para a época. Entre os anos de 30 e 40 a VFRGS inaugurou Estações Ferroviárias padronizadas em diversos pontos do estado.

Com base no que foi apresentado, o objetivo da pesquisa é apresentar a história das ferrovias, primeiramente no cenário mundial, brasileiro e no estado do Rio Grande do Sul. Analisar as estações ferroviárias padrão VFRGS ${ }^{1}$ no período dos anos 30 e 40, verificar se as estações construídas pela VFRGS mantêm uma linguagem arquitetônica semelhante e exemplificar a inserção da estação ferroviária de Alegrete/RS e sua relação coma atualidade.

\section{METODOLOGIA}

O desenvolvimento metodológico aborda a inserção do transporte ferroviário no Brasil e posteriormente no Rio Grande do Sul. É apresentado um breve histórico das ferrovias desde sua origem até a chegada no estado. A partir disso, foram analisadas as estações padrão VFRGS anos 30 e 40, construindo uma linha do tempo para melhor exemplificar as suas semelhanças. Além disso, é relatado o processo de implantação da estação ferroviária de Alegrete/RS.

\section{RESULTADOS E DISCUSSÃO}

\subsection{A ORIGEM DAS FERROVIAS}

No cenário mundial a ferrovia tem seu início a partir da revolução industrial que ocorreu na Inglaterra no século XIX, foi nesse período que se desenvolveram técnicas e máquinas para acelerar os meios de produção. Anteriormente à revolução industrial, há registro de caminhos de ferro interligando as minas, os produtos extraídos eram escoados pelos trilhos utilizando a tração animal para fazer o transporte.

Em 1804 Richard Trevithich constrói a primeira máquina a vapor, porém o transporte ferroviário tem início em 1825 com a linha entre Stockton e Darlington sendo destinado ao transporte de carga. Somente em 1830 a linha entre Liverpool e Machester marca o início do transporte de passageiros (KÜHL,1998). 


\subsection{AS FERROVIAS NO BRASIL}

A implantação do transporte ferroviário no Brasil tem seu início a partir de 1850, quando o império almejava consolidar-se enquanto nação e desvincular-se de Portugal. Mas, as iniciativas para a instalação das estradas de ferro no país começaram já em 1828, quando foi autorizado a exploração das ferrovias no país. Em 1835, houve uma tentativa de interligar os estados de São Paulo, Minas Gerais, Bahia, Rio de Janeiro e Rio Grande do Sul através da lei que concedia privilégio de concessão por 40 anos, a qual não se concretizou. Os prováveis investidores não consideraram um investimento rentável.

A primeira estrada de ferro do Brasil foi empreendida pelo gaúcho Irineu Evangelista Souza, ${ }^{2}$ futuro Barão de Mauá, em 1854, que através da concessão do governo imperial decidiu investir em uma ferrovia que ligasse o Rio de Janeiro até Petrópolis, permitindo a integração entre os transportes ferroviário e hidroviário. ${ }^{3}$

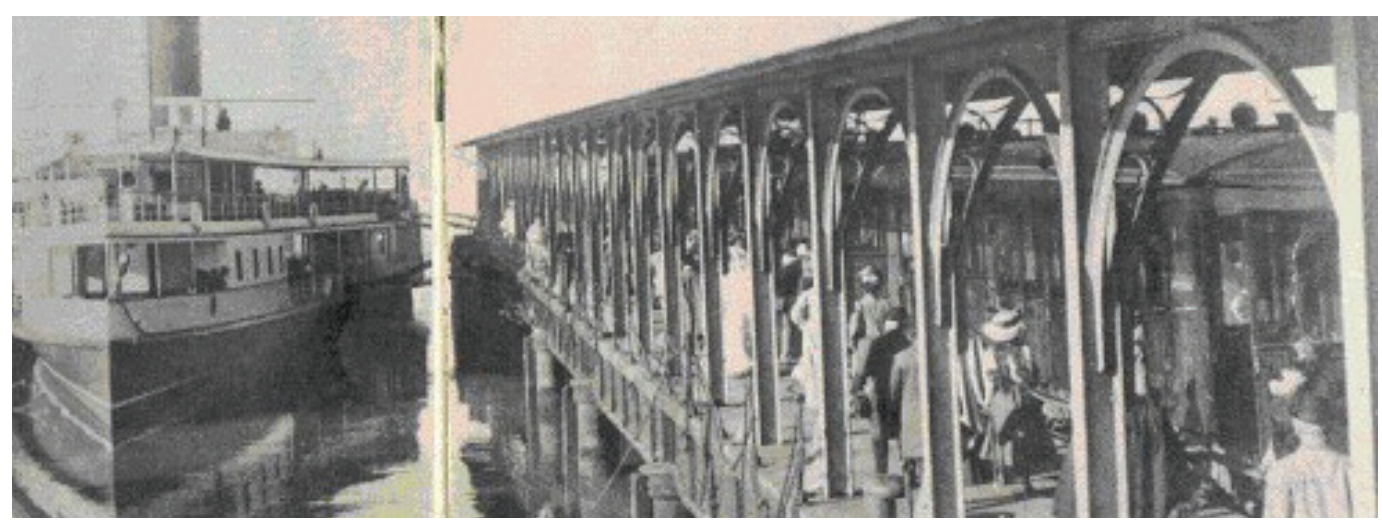

Figura 1: Estrada de Ferro Mauá.

Fonte: https://www.google.com/. Acesso em: 19 abr. 2018

A primeira seção da estrada foi inaugurada por Dom Pedro II em 1854. Segundo Lameira (2010) "A locomotiva Baronesa" - a primeira locomotiva a vapor a funcionar no Brasil -, construída na Inglaterra em 1852, foi utilizada durante 30 anos e hoje se encontra preservada e transformada em monumento cultural." Após a construção da primeira linha ferroviária, as estradas de ferro começaram sua expansão pelo território brasileiro. As ferrovias ao mesmo passo que auxiliou no desenvolvimento do comércio e serviços das cidades, no processo de urbanização, sendo um agente para o surgimento e crescimento de cidades ao mesmo tempo que contribuiu para a decadência de outras cidades que não possuíam ferrovias (CARDOSO; ZAMIN, 2002).

Como exemplo dessas transformações causadas pelas ferrovias no meio urbano, a cidade de São Paulo cresce consideravelmente no final do século XIX, tornando-se um centro convergente de ferrovias. Segundo Cardoso e Zamin (2002) "no rastro das ferrovias vinham uma série de melhoramentos urbanos como, iluminação, telégrafos, escolas jornais e revistas." Ou seja, tornaram-se símbolo de progresso e modernidade.

\subsection{AS FERROVIAS NO RIO GRANDE DO SUL}

Segundo Cardoso e Zamin (2002) "em abril de 1874 foi inaugurada a primeira seção da estrada compreendida entre a Capital e São Leopoldo, com uma extensão de 33.756 metros." Foi construída pela Companhia Inglesa de Johan Mac Ginity e teve como principal 
benefício a multiplicação de núcleos urbanos e o desenvolvimento da produção da zona colonial alemã. Pois a expansão da linha continuou até chegar no município de Canela em 1922 (CARDOSO; ZAMIN, 2002).

Em 1877, quatro anos após a inauguração da estrada Capital São Leopoldo, foi criada uma linha principal, denominada linha tronco, que atravessava o estado horizontalmente e ligava Porto Alegre a Uruguaiana, sendo concluída em 1907.

Segundo Franchi (2017) "Com o passar do tempo, esta linha foi ficando insuficiente e então foram criados os ramais, que eram as linhas ferroviárias que ligavam as cidades até a linha tronco." Um exemplo disso, foi em 1884, as cidades de Rio Grande e Bagé ganhavam um terminal ferroviário para compor a linha "Bagé-Marítima". No ano de 1896 a linha Cacequi-São Gabriel e São Sebastião-São Gabriel completavam a linha Bagé-Rio Grande. Ao mesmo passo que Rio Grande instalava outras rotas, que ligavam à cidade à Costa do Mar e à Estrada do mar. No século XIX muitas linhas férreas foram construídas pelo estado, o que coloca o trem como principal meio de transporte da época.

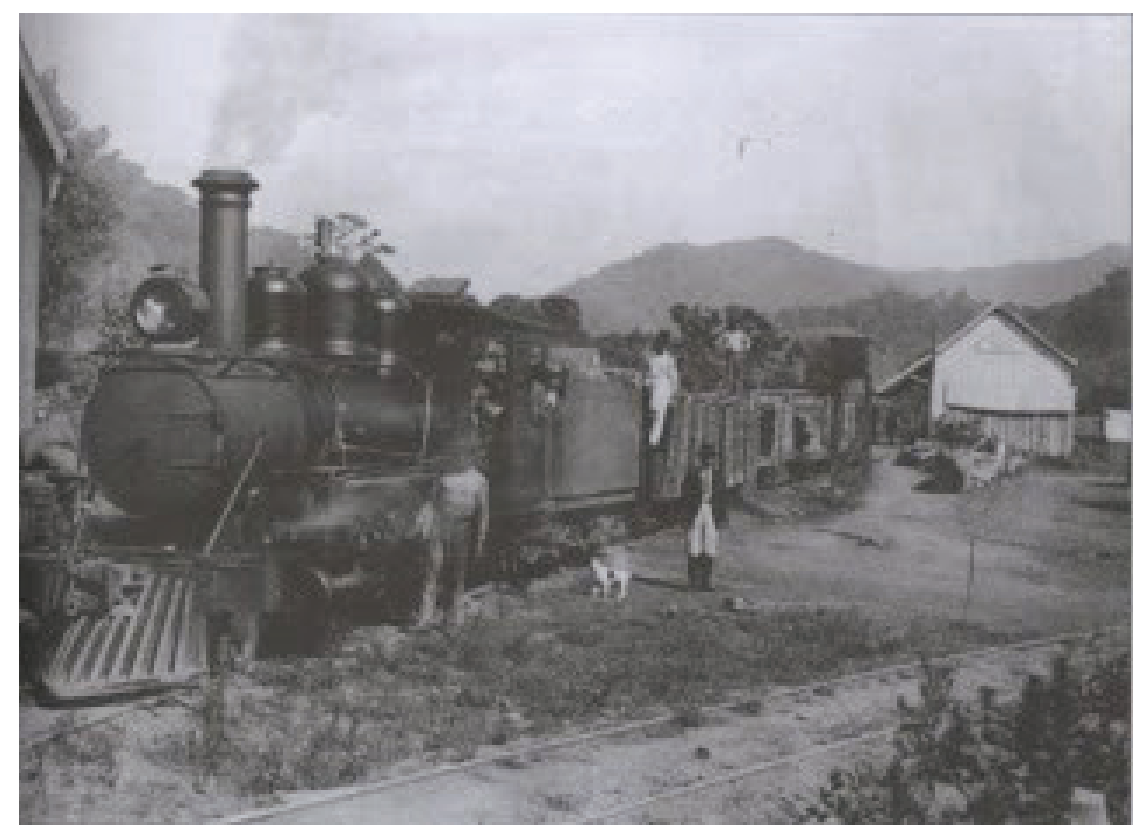

Figura 2: Primeiras Ferrovias do Rio Grande do Sul. Fonte: https://www.google.com/. Acesso em: 19 abr. 2018

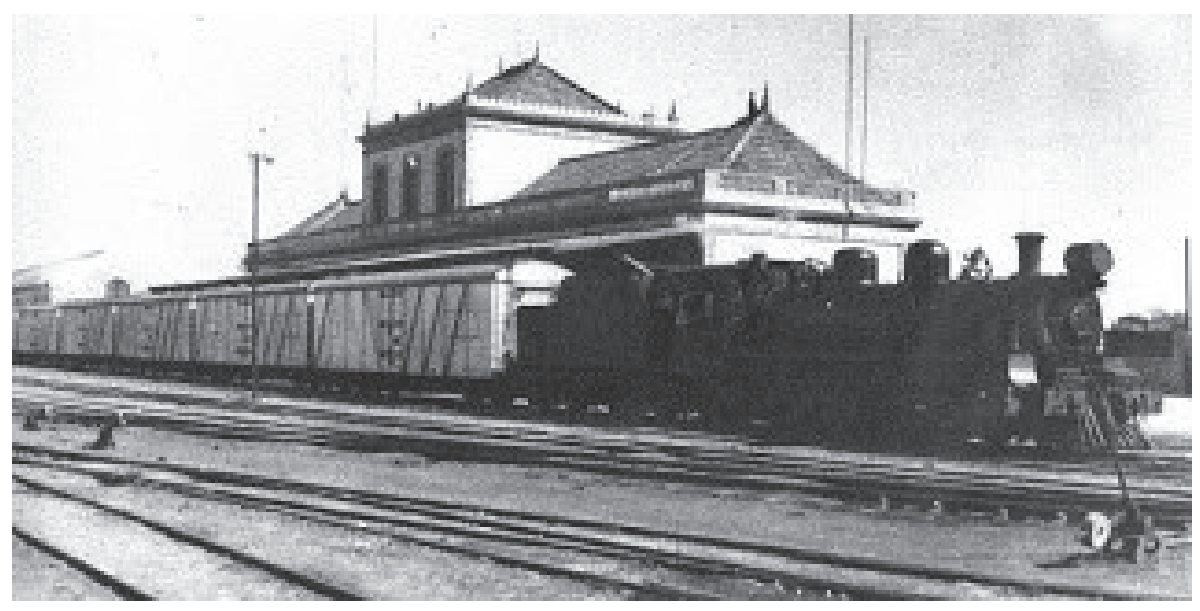

Figura 3: Estação Ferroviária de Rio Grande.

Fonte: https://www.google.com/. Acesso em: 19 abr. 2018 
A união, em julho de 1920, passou para o estado do Rio Grande do Sul a responsabilidade de administrar as ferrovias fixadas no estado, essa tendência aconteceu em todo o país. A Viação Férrea do Rio Grande do Sul foi criada posteriormente, ocasionando um crescimento das linhas ferroviárias no estado, que passaram de $2.300 \mathrm{Km}$ par $3650 \mathrm{Km}$. Eram feitas em torno de 70 viagens de passageiras por dia no Rio Grande do Sul (FRANCHI, 2017).

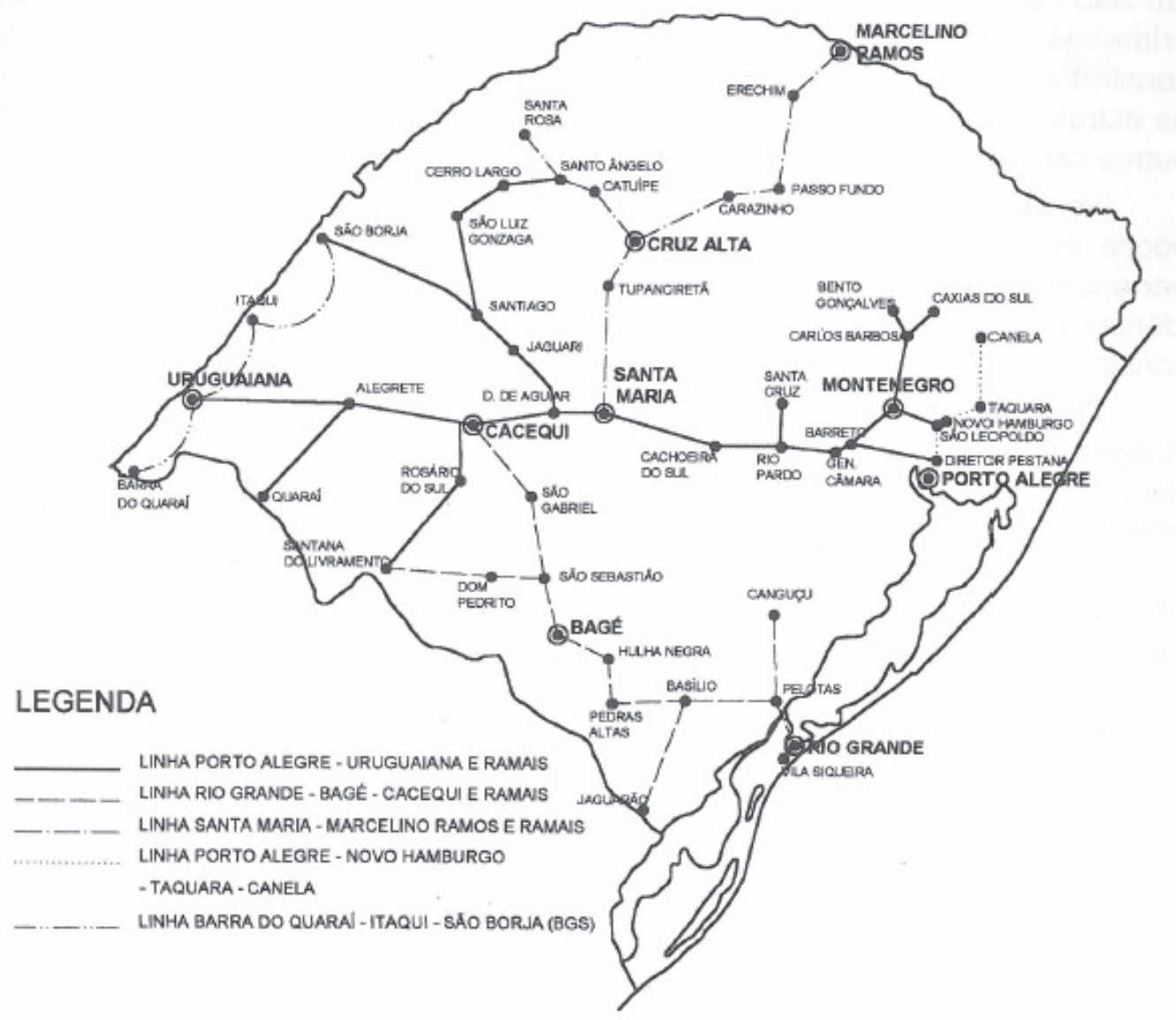

Figura 4: Mapa esquemático da Rede Ferroviária no estado em 1959.

Fonte: Cardoso e Zamin. Patrimônio Ferroviário no Rio Grande do Sul: inventário das Estações 1874-1959 (2002, p. 25)

O período entre 1957 e 1959, foi marcado pela federalização das estradas de ferro no país. As 42 ferrovias existentes no Brasil foram resumidas em 18, sob o comando da Rede Ferroviária Federal Sociedade Anônima (RFFSA). ${ }^{4}$ A viação férrea do Rio Grande Sul (VFRGS), ${ }^{5}$ que passara as estradas de ferro para o sistema nacional, fora extinta posteriormente. Após a federalização houve um avanço no setor ferroviário, com a chegada das locomotivas movidas a diesel, remodelação dos vagões, com o aumento da capacidade e substituição das dormentes de madeira por concreto. Mas, o crescimento da malha rodoviária no país e a desestatização da RFFSA foram fatores importantes para que em 1999 fosse extinta a RFFSA e criada a Agência Nacional de Transporte Terrestre (ANTT), ${ }^{6}$ que atualmente é o órgão que controla e fiscaliza as estradas de ferro no país. Atualmente, as estradas ferro do país não transportam mais passageiros ficando restrito ao uso de cargas.

\subsection{ESTAÇÕES FERROVIÁRIAS}

As estações ferroviárias foram implantadas no mesmo período das linhas férreas, muitas foram construídas por companhias estrangeiras, americanas, belgas, britânicas e, pelos Batalhões de Engenharia do Exército. Os prédios foram compostos por materiais e 
técnicas inovadoras para a época, como o uso de estruturas de ferro importados da Europa como, por exemplo, Estação da Luz, em São Paulo e Estação Central de Belo Horizonte. O ferro, com exceção das duas já citadas, foi utilizado em alguns exemplares como elemento de sustentação e sobre a plataforma de embarque.

Verifica-se a existência de tipologias arquitetônicas específicas em cada época, existindo estações muito semelhantes em cidades diferentes, geralmente pertencentes à mesma linha e à mesma empresa arrendatária. Alguns prédios são idênticos, evidenciando a existência de modelos padronizados aplicados pelos construtores das linhas. (CARDOSO; ZAMIN, 2002, p.26).

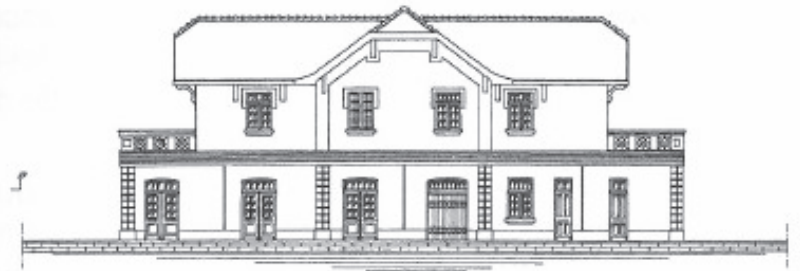

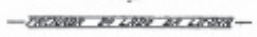
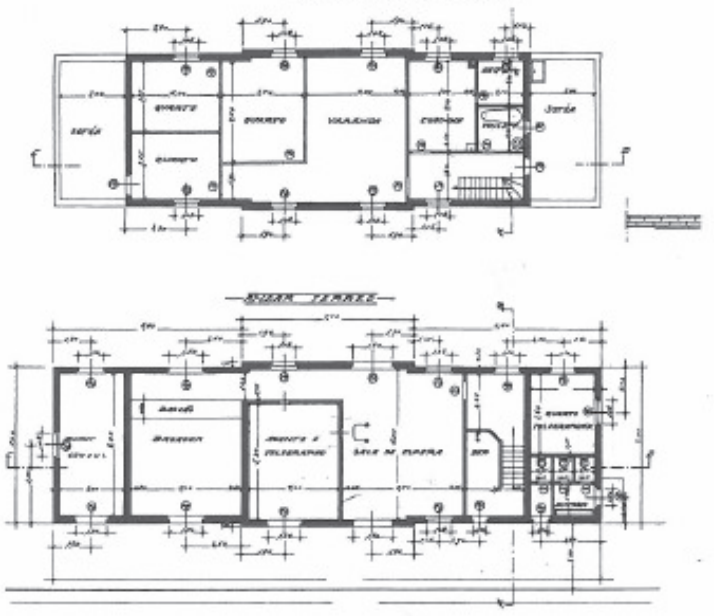
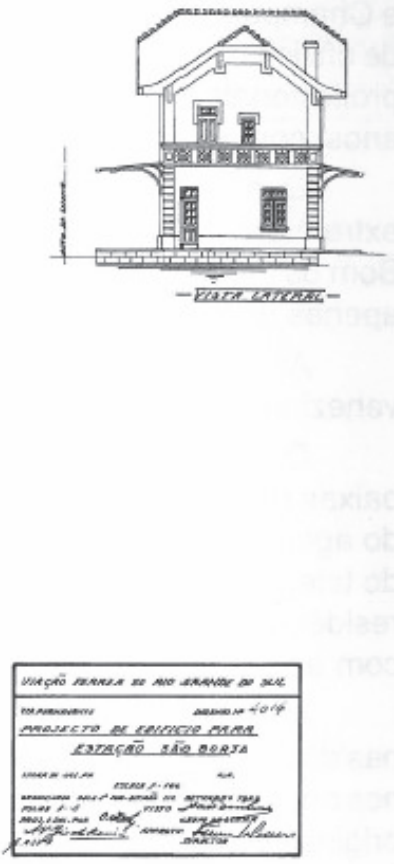

Figura 5: Projeto da Estação de São Borja/RS.

Fonte: Cardoso e Zamin. Patrimônio Ferroviário no Rio Grande do Sul: inventário das Estações 1874-1959 (2002, p. 37)

\subsection{TIPOLOGIA DAS ESTAÇÕES FERROVIÁRIAS}

A tipologia é o estudo científico de tipos e elementos que compõem a linguagem arquitetônica. A tipologia aliada a história, ajuda identificar os costumes de uma sociedade, assim como determina o estilo que a obra está inserida.

$\mathrm{Na}$ arquitetura, referencia-se um tipo de obra, espaço ou parte que compõe o espaço livre, analisando suas variações, escalas e vinculação ao meio urbano, período histórico e abrangência social. São observados os tipos de prédios que não só compreendem os edifícios, mas como ruas, pátios, muros, jardins, entre outros elementos morfológicos. É importante destacar que a arquitetura trabalha a tipologia na escala do edifício ou elemento selecionado (MOTTA; SCOPEL, 2015).

Para Cardoso e Zamin (2002) as estações estão dividas conforme "as características arquitetônicas de cada prédio." Foram agrupadas em grupos que possuem elementos semelhantes, tanto formais quanto funcionais. Este estudo irá detalhar as "estações-padrão VFRGS - anos 30 e 40", constituindo uma linha do tempo para melhor compreensão dos elementos que as compõem. 
É importante salientar que a ordem cronológica das estações está organizada de acordo com o ano de inauguração da linha férrea, pois em alguns casos, como Alegrete, Cacequi, Jaguari, São Borja e Dom Pedrito, já existiam estações ferroviárias anteriormente as décadas de 1930 e 1940. As quais passaram por reforma onde foi implementado o projeto da VFRGS.

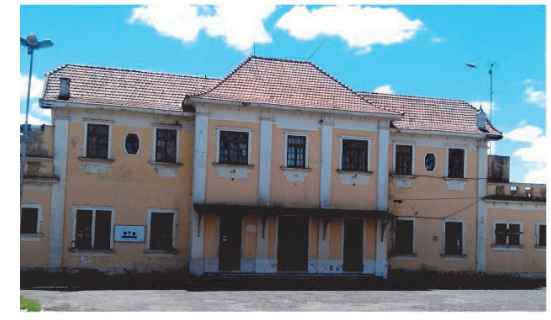

ミstação Ferroviária de Alegrete

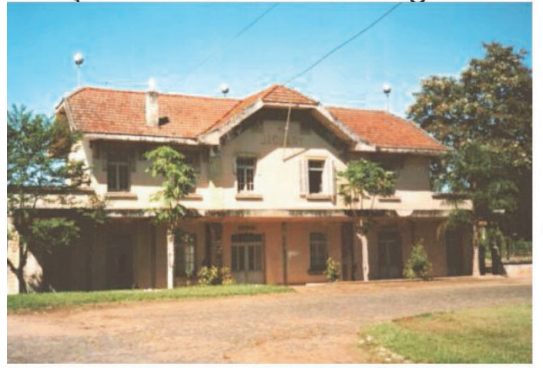

:stação Ferroviária de Jaguari

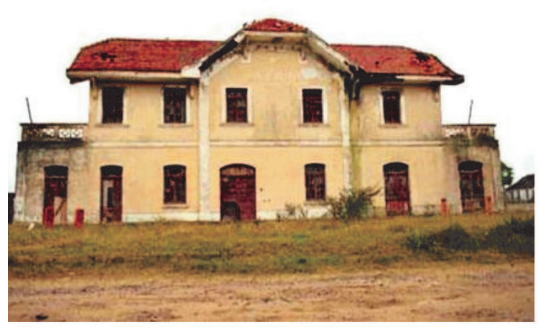

Estação Ferroviária de Jaguarão

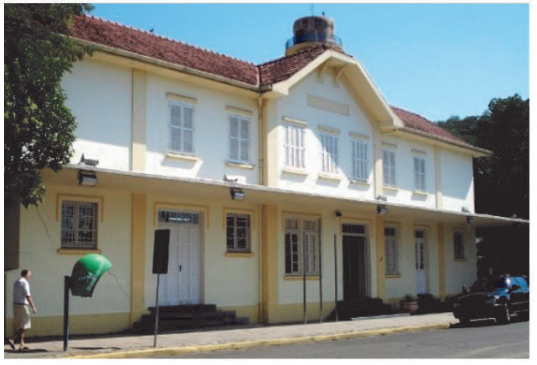

stação Ferroviária de Campo Bom

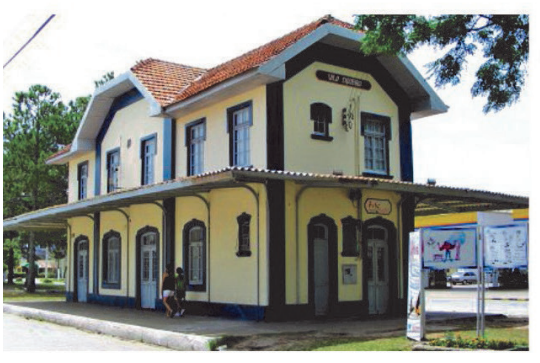

;tação Ferroviária de Villa Siqueira

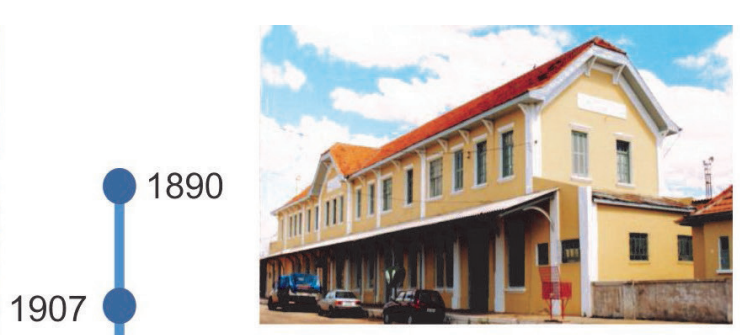

Estação Ferroviária de Cacequi

1913

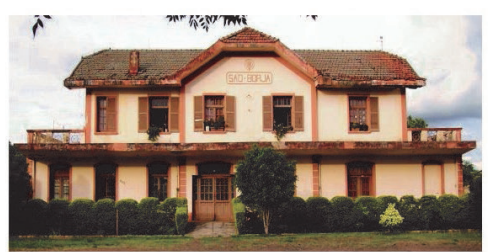

Estação Ferroviária de São Borja

1923

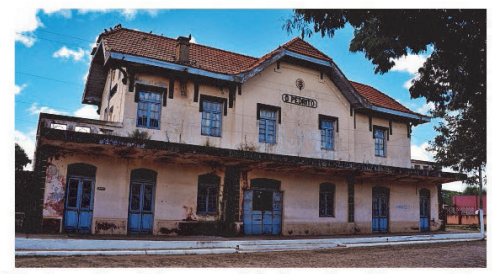

Estação Ferroviária de Dom Pedrito

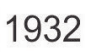

1935

1934

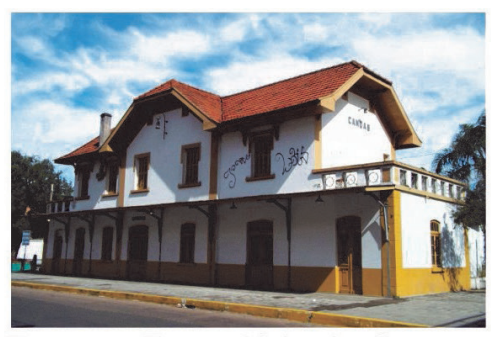

Estação Ferroviária de Canoas

1935

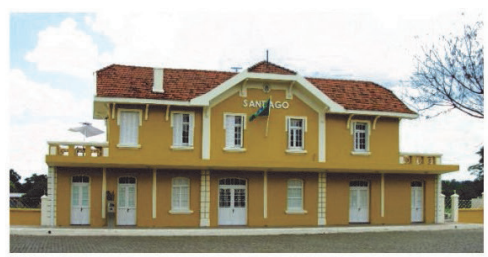

Estação Ferroviária de Santiago

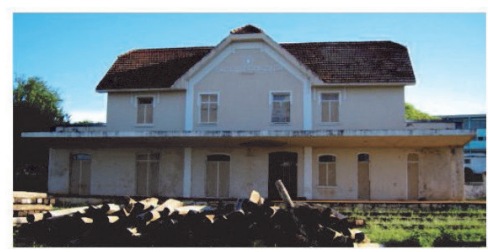

Estação Ferroviária de São Luiz Gonza

Tabela 1: Linha do tempo das estações ferroviárias padrão VFRGS Fonte: Autor.

Segundo Cardoso e Zamin (2002) "estes prédios foram inaugurados nas décadas de 
30 e 40 pela VFRGS, constituindo um projeto padrão." Foram construídos para substituir estações antigas em diversos pontos do estado.

O programa básico destas estações, tomando-se como modelo as plantas baixas das estações de Cacequi, São Borja e Canoas, inclui sala de espera, sala do agente telégrafo, setor de atendimento com depósito para bagagens, quarto do telegrafista e sanitários no andar térreo. No pavimento superior localizava-se a residência do agente, com "Varanda", cozinha, despensa, toilete e três dormitórios com acesso aos terraços laterais. (CARDOSO; ZAMIN, 2002, p.38).

O aspecto formal desses prédios é característico, pois é distinto das outras estações do estado. As coberturas possuem múltiplas águas, com alta inclinação, telhas do tipo francesa, os telhados triangulares possuindo grandes beirais. Os prédios estão distribuídos em dois pavimentos, e inseridos paralelamente à via férrea. Possuem um corpo central com duas ou três janelas e dois corpos laterais com dimensões variáveis. Quase todas possuem terraços descobertos nas duas extremidades. As esquadrias no $2^{\circ}$ pavimento são de verga reta, janelas com veneziana. No primeiro pavimento as esquadrias contêm arco abatido com bandeira de vidro fixo (CARDOSO; ZAMIN, 2002).

Não é possível determinar a autoria desses projetos padrões, visto que os selos dos projetos se encontram ilegíveis. O que se pode perceber é que as estações possuem teIhados inclinados com traços alemães. Entre as décadas de 20 e 40, havia profissionais da VFRGS com origem alemã, como o desenhista Eram Arno C. Obst e o engenheiro Arno Deppermann. Este foi um profissional atuante em Porto Alegre no período de 1920-1950, tendo feito casas, os colégios Rosário e Champagnat. O que se pode perceber é que talvez a origem germânica desses profissionais explique o modelo de estação reproduzida pela VFRGS (CARDOSO; ZAMIN, 2002).

\section{ESTAÇÃO FERROVIÁRIA DE ALEGRETE-RS}

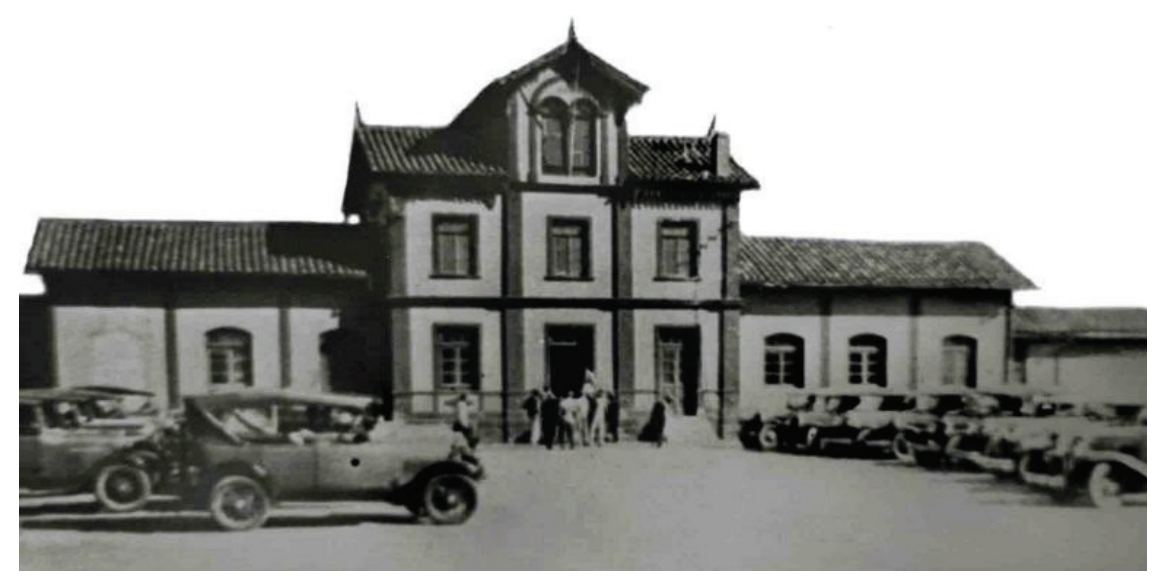

Figura 6: Estação ferroviária de Alegrete na década de 1920.

Fonte: https://www.google.com/. Acesso em 19 abr. 2018

A estação ferroviária de Alegrete/RS integra a linha Porto Alegre - Uruguaiana, na qual a implantação é determinada pelo Decreto Imperial 2397/1873. O decreto determinava a construção de uma estrada que interligasse a Capital com o litoral e interior. No mesmo ano o Governo Imperial firmou contrato com os concessionários: Cristiano Benedito Ottoni, ${ }^{7}$ Herculano Veloso Ferreira ${ }^{8}$ e Caetano Furquim de Almeida9 (CARDOSO; ZAMIN, 2002). 
gar de franca navegação do Rio Jacuí". As obras que eram contratadas por empresas parciais iniciaram em 1877, na margem direita do Rio Taquari, rumo a fronteira oeste do estado, atingindo Cacequi em 1890. (CARDOSO; ZAMIN, 2002, p.87).

Em 1898 o trecho Uruguaiana - Alegrete, que formavam a linha Porto Alegre - Uruguaiana, estava com $105 \mathrm{~km}$ concluídos sendo utilizados para o comércio regional de forma provisória. O trecho entre Alegrete e Cacequi só foi finalizado em 1907. Segundo Cardoso e Zamin (2002) "Já em 1902 tinha-se notícias de uma estação ferroviária em Alegrete, que estaria localizada na parte norte da cidade, no fim da rua Luiz de Freitas Valle."

Em 1912, a população demonstrou-se contrária em relação ao sítio da estação ferroviária, queriam que a futura estação fosse instalada na zona sul da cidade. As reivindicações foram aceitas pela direção da estrada de ferro, resolvendo instalar a nova estação na região da Coxilha Seca, ao sul da rua Barros Cassal, atualmente rua Conde de Porto Alegre. Além disso, o planejamento das linhas ferroviárias sofreu interferência dos moradores locais, pois a ferrovia iria passar por parte da propriedade dos moradores. Após uma sequência de discussões com a prefeitura, estado e construtores o traçado foi transposto para oeste da cidade, não lesando os proprietários e tão pouco o traçado da cidade. É importante salientar que não há informações da data em que foi construído o segundo prédio da estação. Para Leandro Telles, historiador a estação teria passado por reformas em 1934. (CARDOSO; ZAMIN, 2002).

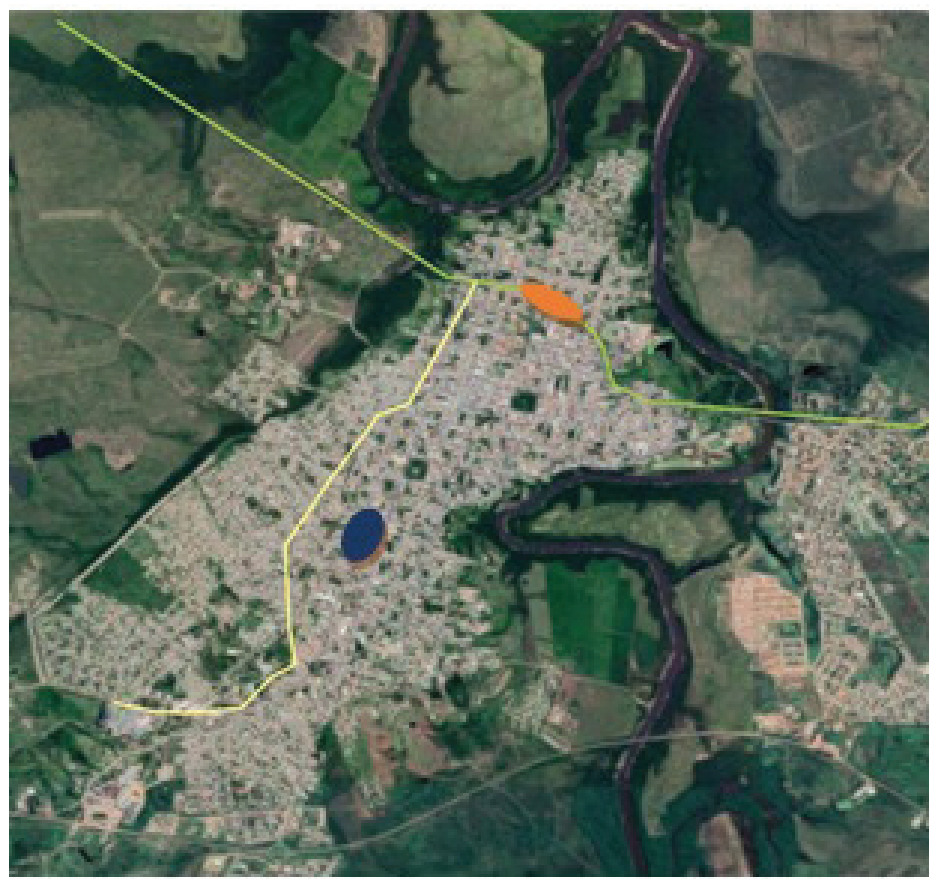

Figura 7: Inserção na malha urbana. Fonte: https://www.google.com/. Acesso em: 03 mar. 2018

LEGENDA:

Estação Ferroviária de Alegrete.

Proposta de Implantação em 1912.

Linha industrial.

Linha cacequi $x$ Uruguaiana. 
Observa-se na figura 7 um esquema demonstrando em laranja a posição da estação ferroviária atual, com a linha principal, em verde, ligando os municípios de Cacequi a nordeste e Uruguaiana a noroeste. A linha industrial, escoa a produção de arroz por dentro da malha urbana até chegar à estação e ser distribuída. Além disso, em azul está marcada a proposta de implantação da segunda estação ferroviária em 1912, exemplificando a decisão de não interferir no traçado da cidade.

Infelizmente, não há relatos de empresas, serviços e de estruturação urbana que vieram a se desenvolver por meio da estrada de ferro no município. O que se analisou foi a intenção do município em não deslocar o eixo ferroviário para não interferir no desenho urbano da cidade.

Além disso, a estética original do prédio, remete a linguagem dos chalés, estilo vigente entre o final do século XIX e início do século XX. Essa linguagem é evidenciada nos telhados de duas águas com lambrequins e pelo volume central mais alto, remetendo a um mirante (CARVALHO, 2017).

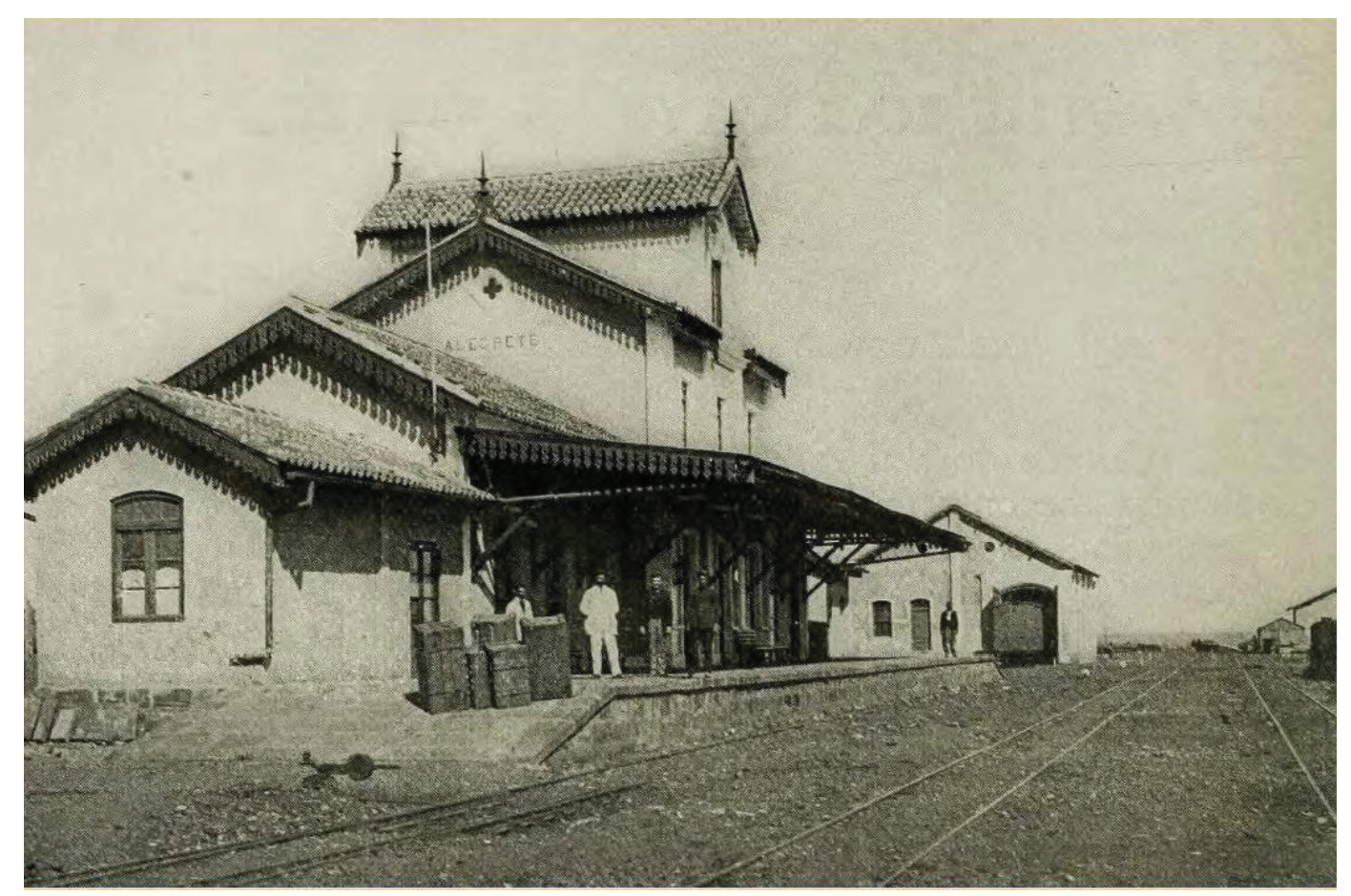

Figura 8: Estação ferroviária de Alegrete antes da reforma. Fonte: https://www.google.com/. Acesso em: 19 abr. 018

Na década de 1930 o prédio da estação ferroviária passou por uma reestruturação e reforma que culminou na descaracterização do prédio. O volume central e os lambrequins foram removidos, possibilitando a ampliação do segundo pavimento, dando lugar a um corpo central com varandas nas extremidades, apoiadas no volume térreo. Também neste mesmo período foi erguido um armazém, ao lado do prédio da estação, para armazenagem de cargas (CARVALHO, 2017). 

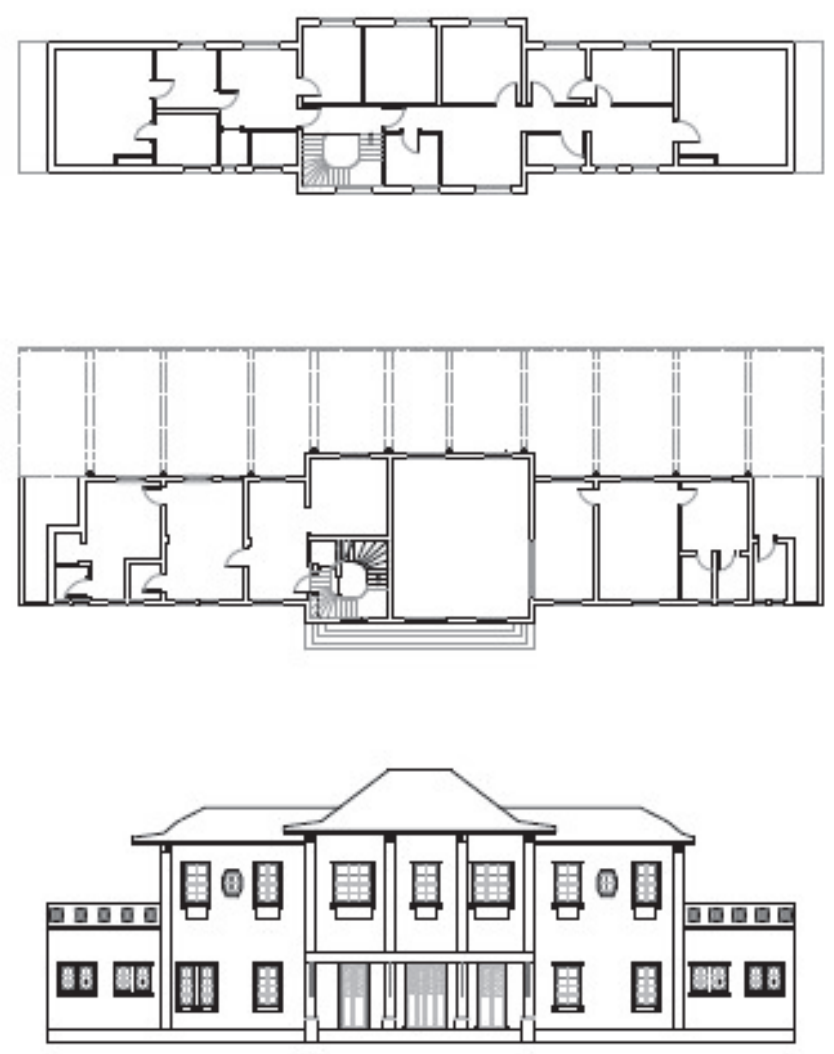

Figura 9: Plantas Baixas e Fachada da Estação Ferroviária de Alegrete. Fonte: Autor

Segundo Carvalho (2017) "transitavam por essa estação trens de carga e de passageiros, porém, em 1996 foi decretado o fim do transporte de pessoas, ano em que, infelizmente, também marcou o início do abandono e deterioração do prédio principal e do galpão da Estação." A partir de 1999, é desativado o transporte de passageiros na estação. Permanecendo, desde então, o transporte de cargas, principalmente arroz, que foi mantida pela empresa $\mathrm{ALL}^{10}$ até 2015 . Atualmente a Estação Ferroviária está sob a responsabilidade do DNIT, ${ }^{11}$ não transportando de cargas na estação. Por esse motivo e também por falta de investimentos o prédio encontra-se em estado de abandono e deterioração.

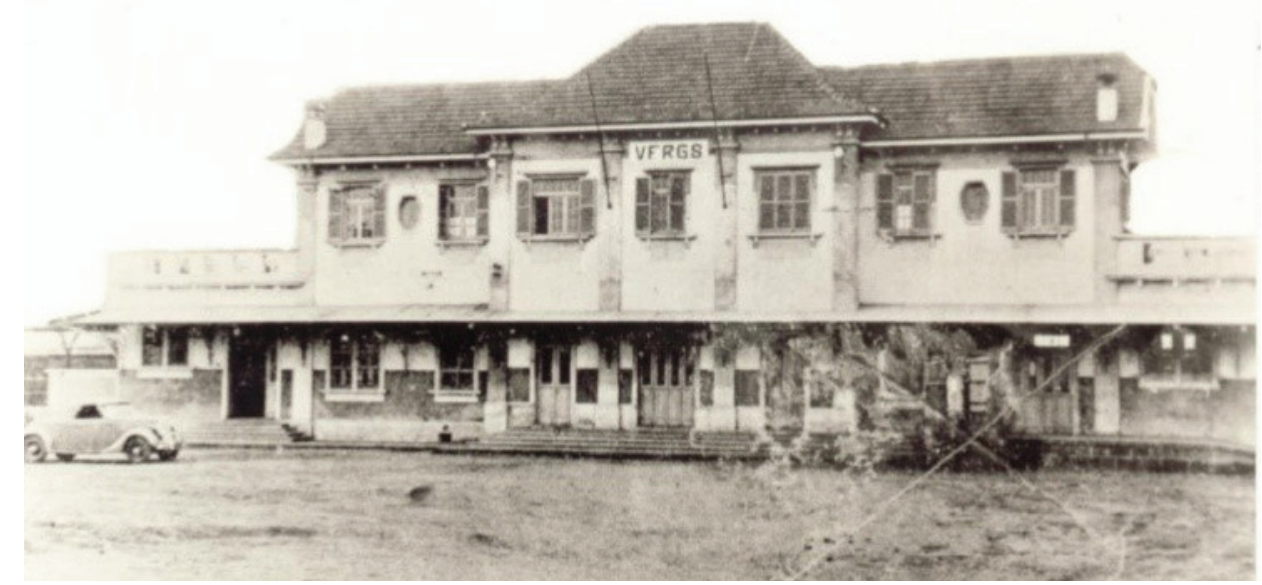

Figura 10: Estação ferroviária de Alegrete posterior a reforma, na década de 1930. Fonte: https://www.google.com/. Acesso em: 19 abr. 2018 


\section{CONCLUSÃO}

Conclui-se que a origem das ferrovias nos cenários internacional, nacional e regional constitui-se como sinônimo de desenvolvimento econômico e social para as regiões onde as linhas férreas estão inseridas. As estações ferroviárias analisadas, embora com algumas variáveis, seguem um projeto padrão, que resulta em estações férreas com forte identidade visual. Em Alegrete/RS, ainda que implantação da segunda estação ferroviária sofresse resistência por parte da população, a decisão em não alterar o traçado da cidade em função da malha ferroviária prevaleceu.

\section{NOTAS}

1. Viação Férrea do Rio Grande do Sul, empresa estatal administrada pelo governo do Rio Grande do Sul entre 1920-1959.

2. Nascido em Arroio Grande, Rio Grande do Sul, construiu estaleiros em Niterói, iniciando a indústria naval brasileira.

3. Mais tarde a estrada passou a se chamar "Estrada de Ferro Mauá".

4. Rede Ferroviária Federal sociedade anônima (RFFSA) foi uma empresa estatal brasileira de transporte ferroviário, com sede na cidade do Rio de Janeiro.

5. Viação Férrea do Rio Grande do Sul (VFRGS) foi uma empresa estatal sul-riograndense que administrou a rede ferroviária do estado entre 1920-1959.

6. Agência Nacional de Transporte Terrestre (ANTT) é um órgão federal responsável pela regulação e exploração da infraestrutura ferroviária e rodoviária Federal.

7. Cristiano Benedito Ottoni, foi capitão-tenente da Marinha, engenheiro, professor de Matemática e diretor da Estrada de Ferro Dom Pedro II.

8. Herculano Veloso Ferreira, foi professor, e político brasileiro.

9. Caetano Furquim de Almeida, foi um advogado, banqueiro e empresário brasileiro.

10. América Latina Logística, empresa de transporte e logística, atual RUMO.

11. Departamento Nacional de Infraestrutura e Transportes.

\section{REFERÊNCIAS}

CARDOSO, Alice; ZAMIN, Frinéia (Org.). Patrimônio ferroviário no Rio Grande do Sul: inventário das estações 1874-1959. Instituto do Patrimônio Histórico e Artístico do Estado da Secretaria da Cultura do RS. Porto Alegre: Palotti, 2002

CARVALHO, Carolina F.C. Revitalização da Estação Ferroviária de Alegrete. Porto Alegre: edUFRGS, 2017.

FRANCHI, Diones. A Ferrovia no Rio Grande do Sul. Memórias do Pampa, Bagé, 31 jul. 2017. Disponível em: file:///D:/Documents/Arquitetura\%209\%C2\%B0\%20semestre/TCC1-/Links\%20de\%20Pesquisa/ Mem\%C3\%B3rias\%20do\%20Pampa_\%20A\%20ferrovia\%20no\%20Rio\%20Grande\%20do\%20Sul.html. Acesso em: 23 abr. 2019. 
KÜHL, Beatriz Mugayar. Arquitetura do ferro e arquitetura ferroviária em São Paulo: reflexões sobre a sua preservação. São Paulo: Ateliê editorial: Fapesp: Secretaria da Cultura, 1998.

LAMEIRA, Márlon Martin. O Patrimônio Ferroviário do Rio Grande do Sul e os Critérios de Preservação. 2010. Monografia (Especialização em Arquitetura e Patrimônio Arquitetônico no Brasil) Pontifícia Universidade Católica do Rio Grande do Sul, Porto Alegre, 2010.

MOTTA, Juliana; SCOPEL, Vanessa. Aspectos da tipologia na Arquitetura. [S.I]: Uniritter. Disponível em:https://www.uniritter.edu.br/files/sepesq/arquivos_trabalhos/3612/927/1070-.pdf. Acesso em: 23 maio 2018.

Recebido em: 15/06/2019

Aceito em: 07/07/2019 